\title{
Fast ion conduction and its origin in $\mathrm{Li}_{6-\mathrm{x}} \mathbf{P S}_{5-\mathrm{x}} \mathrm{Br}_{1+\mathrm{x}}$
}

Pengbo Wang, ${ }^{\dagger}$ Haoyu Liu, ${ }^{\dagger}$ Sawankumar Patel, ${ }^{\dagger}$ Xuyong Feng, ${ }^{\dagger}$ Po-Hsiu Chien, ${ }^{+,+}$Yan Wang, ${ }^{\Phi, \perp}$ and Yan-Yan $\mathrm{Hu}^{*,+,+}$

${ }^{+}$Department of Chemistry and Biochemistry, Florida State University, Tallahassee, FL 32306, USA.

${ }^{\ddagger}$ Center of Interdisciplinary Magnetic Resonance, National High Magnetic Field Laboratory, 1800 East Paul Dirac Drive, Tallahassee, FL 32310, USA

${ }^{\S}$ Advanced Material Lab, Samsung Research America, 3 Van de Graaff Drive, Burlington, MA 01803, USA

${ }^{\perp}$ Department of Material Science and Engineering, Massachusetts Institute of Technology, 77 Massachusetts Ave, Cambridge, MA 02139, USA

Table S1. Crystallographic information of $\mathrm{Li}_{6} \mathrm{PS}_{5} \mathrm{Br}$ (atomic coordinates, site occupancy, and $\mathrm{U}_{\text {iso }}$ ), obtained from Rietveld Refinement of X-ray diffraction.

\begin{tabular}{|c|c|c|c|c|c|c|}
\hline \multicolumn{7}{|c|}{$\begin{array}{l}\left.\mathrm{Li}_{6} \mathrm{PS}_{5} \mathrm{Br} \text { structure from X-ray diffraction data (space group } F-43 \mathrm{~m}\right) \\
\mathrm{a}=9.969976 \\
\chi^{2}=1.55 \\
\mathrm{R}_{\mathrm{wp}}=7.273 \%\end{array}$} \\
\hline Atom & Wyckoff site & $\mathrm{x}$ & $\mathrm{y}$ & $\mathrm{z}$ & Fraction & $\mathrm{U}_{\text {iso }}$ \\
\hline Li1 & $48 \mathrm{~h}$ & 0.307100 & 0.025100 & 0.692900 & 0.407 & 0.0557 \\
\hline $\mathrm{Li} 2$ & $24 \mathrm{~g}$ & 0.250000 & 0.017000 & 0.750000 & 0.148 & 0.0557 \\
\hline $\mathrm{P} 1$ & $4 \mathrm{~b}$ & 1.000000 & 0.500000 & 1.000000 & 1.000 & 0.0366 \\
\hline S1 & $16 \mathrm{e}$ & 0.119772 & -0.119772 & 0.619772 & 1.000 & 0.0440 \\
\hline S2 & $4 \mathrm{~d}$ & 0.750000 & 0.750000 & 0.750000 & 0.756 & $0.0367(17)$ \\
\hline S3 & $4 a$ & 1.000000 & 1.000000 & 1.000000 & 0.244 & $0.0475(21)$ \\
\hline Br1 & $4 a$ & 1.000000 & 1.000000 & 1.000000 & 0.756 & $0.0367(17)$ \\
\hline $\mathrm{Br} 2$ & $4 \mathrm{~d}$ & 0.750000 & 0.750000 & 0.750000 & 0.244 & $0.0475(21)$ \\
\hline
\end{tabular}

Table S2. Atomic arrangement in a $2 \times 1 \times 1$ supercell of $\mathrm{Li}_{6_{-x}} \mathrm{PS}_{5-x} \mathrm{Br}_{1+x}$ for Density Function Theory calculations.

\begin{tabular}{|l|l|l|l|l|l|l|l|l|}
\hline \multicolumn{2}{|l|}{ Number of atoms in a $2 \times 1 \times 1$ supercell } \\
\hline \multirow{2}{*}{$\mathrm{x}$ in $\mathrm{Li}_{6-\mathrm{x}} \mathrm{PS}_{5-\mathrm{x}} \mathrm{Br}_{1+\mathrm{x}}$} & 0 & 0.125 & 0.25 & 0.375 & 0.5 & 0.625 & 0.75 \\
\hline $\mathrm{Li}$ & total & 48 & 47 & 46 & 45 & 44 & 43 & 42 \\
\hline $\mathrm{S}$ & total & 40 & 39 & 38 & 37 & 36 & 35 & 34 \\
\cline { 2 - 9 } & $4 \mathrm{a}$ & 3 & 2 & 1 & 0 & 0 & 0 & 0 \\
\cline { 2 - 9 } & $4 \mathrm{~d}$ & 5 & 5 & 5 & 5 & 4 & 3 & 2 \\
\hline \multirow{3}{*}{$\mathrm{Br}$} & total & 8 & 9 & 10 & 11 & 12 & 13 & 14 \\
\cline { 2 - 9 } & $4 \mathrm{a}$ & 5 & 6 & 7 & 8 & 8 & 8 & 8 \\
\cline { 2 - 9 } & $4 \mathrm{~d}$ & 3 & 3 & 3 & 3 & 4 & 5 & 6 \\
\hline
\end{tabular}




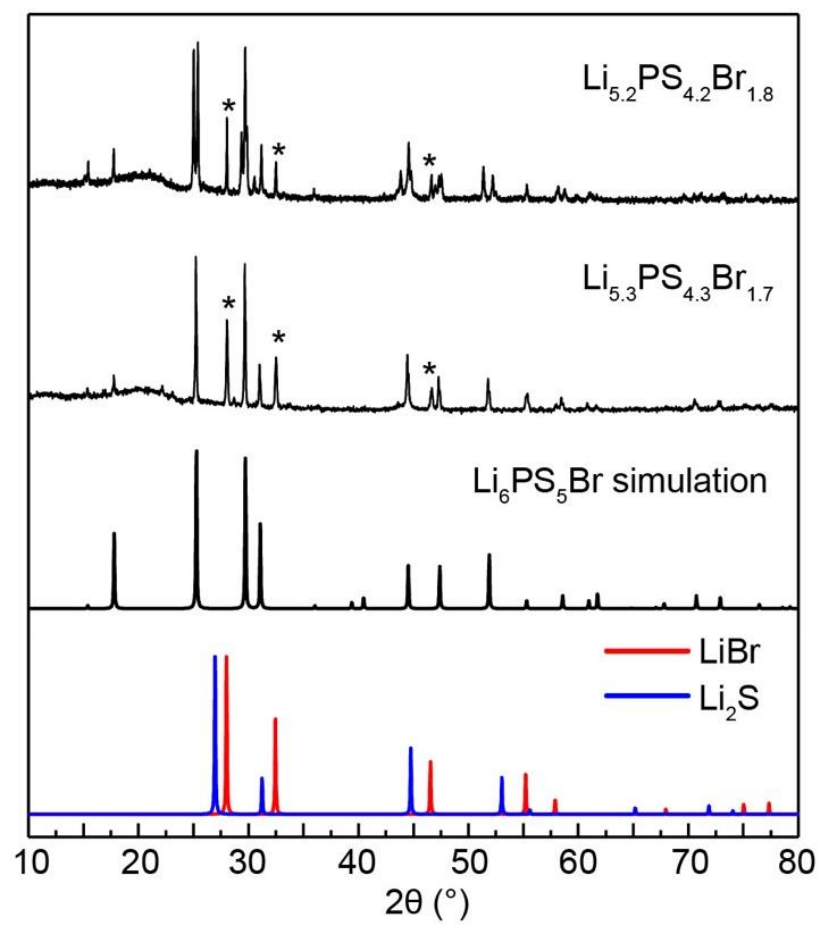

Figure S1. X-ray diffraction patterns of $\mathrm{Li}_{5.3} \mathrm{PS}_{4.3} \mathrm{Br}_{1.7}$ and $\mathrm{Li}_{5.2} \mathrm{PS}_{4.2} \mathrm{Br}_{1.8}$. Peaks from $\mathrm{LiBr}$ are annotated with asterisks. The estimated amount of $\mathrm{LiBr}$ from $\mathrm{Li}_{5.3} \mathrm{PS}_{4.3} \mathrm{Br}_{1.7}$ is $18 \%$ based on Rietveld refinement.

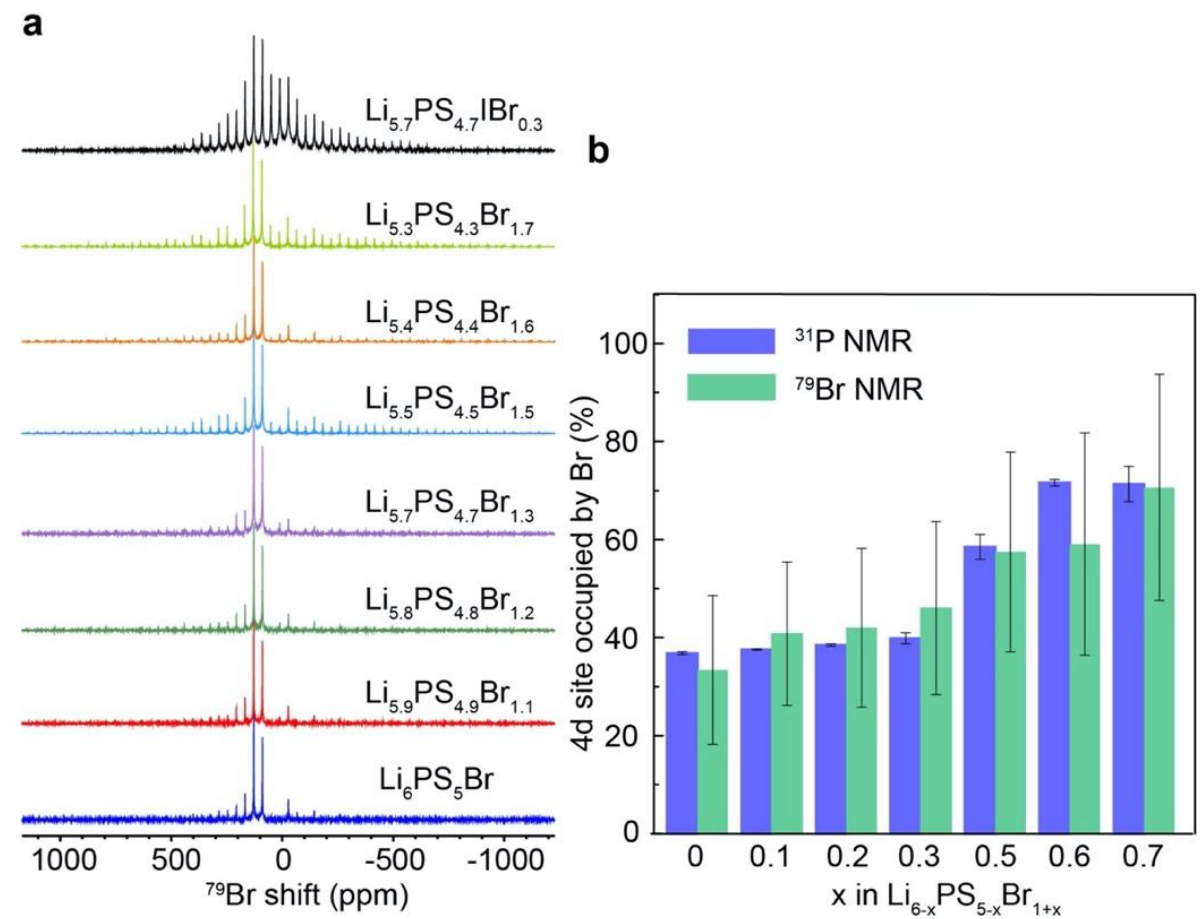

Figure S2. (a) ${ }^{79} \mathrm{Br}$ static QCPMG NMR spectra of $\mathrm{Li}_{6-\mathrm{x}} \mathrm{PS}_{5-\mathrm{x}} \mathrm{Br}_{1+\mathrm{x}}(0 \leq x \leq 0.7)$ and $\mathrm{Li}_{5.7} \mathrm{PS}_{4.7} \mathrm{IBr}_{0.3 .}$. (b) Summary of $4 \mathrm{~d}$ site occupancies by $\mathrm{Br}$ obtained by ${ }^{31} \mathrm{P} \mathrm{NMR}$ and ${ }^{79} \mathrm{Br} \mathrm{NMR}$, respectively. 
To understand the observed ${ }^{6} \mathrm{Li} \mathrm{NMR}$ (Fig. 3a), two $\mathrm{Li}_{6} \mathrm{PS}_{5} \mathrm{Br}$ structures without anion mixing were simulated: $\mathrm{Li}$ ions locate 1) exclusively at $24 \mathrm{~g}$ and 2) exclusively at $48 \mathrm{~h}$, respectively, while, the remaining structural framework was kept the same. In 1 ), $\mathrm{Li}$ ions fully occupy $24 \mathrm{~g}$ sites and their chemical environments are identical. However, in 2 ), Li ions can only occupy half of the $48 \mathrm{~h}$ sites. Due to the intrinsic symmetry, those Li ions cannot be distributed evenly in the unit cell and some of the Li ions are closer than the others.

Unlike the method shown in the main text, NMR calculations here were performed without structural relaxation to make sure that $\mathrm{Li}$ ions were positioned at specified Wyckoff sites. The calculated results were visualized in Figure S3 with MagresView. ${ }^{1}$ Overall, the $24 \mathrm{~g} \mathrm{Li}$ ions show larger NMR chemical shifts than the $48 \mathrm{~h} \mathrm{Li}$ ions, and $48 \mathrm{~h} \mathrm{Li}$ ions exhibit broader distribution in chemical shifts. Closer examination reveals that the shifts are directly related to the distance to their neighboring $\mathrm{Li}$ ions and the number of the neighboring $\mathrm{Li}$ ions (Table S3). The absence of neighboring Li results in small chemical shifts. Li deficiency reduces the number of neighboring Li ions, and the overall ${ }^{6} \mathrm{Li}$ shift decreases consistent with experiments. In addition, based on both the experiments and calculated shifts, each Li ion should be surrounded by at least another Li ion within $2.5 \AA$ range.

Table S3. Li isotropic chemical shifts of different Li ions and the distance to their neighboring Li ions (within $3 \AA$ ) in $\mathrm{Li}_{6} \mathrm{PS}_{5} \mathrm{Br}$ structure with $\mathrm{Li}$ located exclusively at $48 \mathrm{~h}$ sites.

\begin{tabular}{|c|c|c|c|}
\hline \multirow{2}{*}{$\begin{array}{l}\text { Li isotropic shift } \\
(\mathrm{ppm})\end{array}$} & \multicolumn{3}{|c|}{ Distance to neighboring $\mathrm{Li}(\AA)$} \\
\hline & 1st $\mathrm{Li}$ & 2nd $\mathrm{Li}$ & $3 \mathrm{rd} \mathrm{Li}$ \\
\hline 1.88 & 2.35 & 2.86 & 2.86 \\
\hline 1.87 & 2.35 & 2.86 & 2.86 \\
\hline 1.68 & 2.35 & 2.86 & - \\
\hline 1.67 & 2.35 & 2.86 & - \\
\hline 1.66 & 2.35 & 2.86 & - \\
\hline 1.66 & 2.35 & 2.86 & - \\
\hline 1.63 & 2.35 & 2.86 & - \\
\hline 1.61 & 2.35 & 2.86 & - \\
\hline 1.60 & 2.35 & 2.86 & - \\
\hline 1.59 & 2.35 & 2.86 & - \\
\hline 1.54 & 2.35 & 2.86 & - \\
\hline 1.51 & 2.35 & 2.86 & - \\
\hline 1.37 & 2.35 & - & - \\
\hline 1.37 & 2.35 & - & - \\
\hline 1.31 & 2.35 & - & - \\
\hline 1.30 & 2.35 & - & - \\
\hline 1.00 & & 2.86 & 2.86 \\
\hline 0.79 & & 2.86 & \\
\hline 0.78 & - & 2.86 & - \\
\hline 0.58 & & - & \\
\hline 0.55 & & - & \\
\hline 0.54 & - & & \\
\hline 0.52 & & - & \\
\hline 0.48 & & - & \\
\hline
\end{tabular}




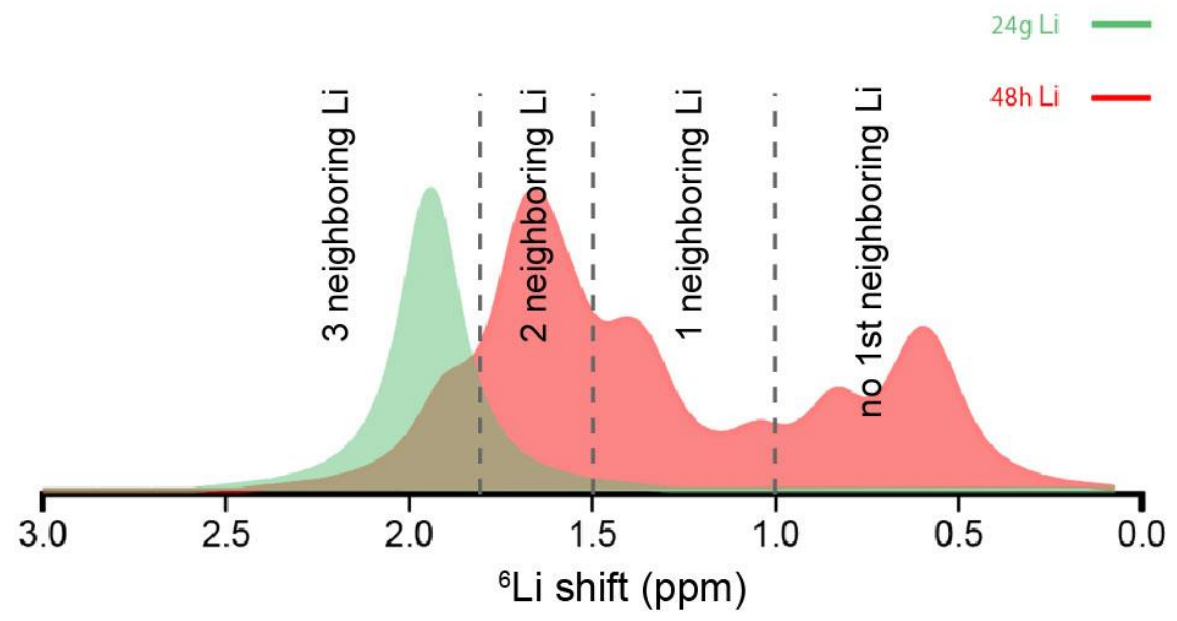

Figure S3. Calculated ${ }^{6} \mathrm{Li}$ NMR shifts for two different $\mathrm{Li}_{6} \mathrm{PS}_{5} \mathrm{Br}$ structures: 1) only $24 \mathrm{~g}$ and 2) only $48 \mathrm{~h}$ sites are occupied by Li.

Table S4. Limiting jump rates of $\mathrm{Li}^{+}$of different configurations at $4 \mathrm{~d}$ sites in $\mathrm{Li}_{6} \mathrm{PS}_{5} \mathrm{Cl}^{2}$

\begin{tabular}{llllll}
\hline Cl occupancy at $4 \mathrm{c}$ sites $(\%)$ & 0 & 25 & 50 & 75 & 100 \\
\hline $4 \mathrm{~d}$ configuration & $4 \mathrm{~S}$ & $3 \mathrm{~S} 1 \mathrm{Cl}$ & $2 \mathrm{~S} 2 \mathrm{Cl}$ & $1 \mathrm{~S} 3 \mathrm{Cl}$ & $4 \mathrm{Cl}$ \\
Limiting step & - & intercage & intercage & intercage & doublet \\
Limiting Jump rate $\left(10^{9} \mathrm{~s}^{-1}\right)$ & - & 17.9 & 31.2 & 62 & 2.1 \\
\hline
\end{tabular}

Table S5. Overall jump rates in $\mathrm{Li}_{6-x} \mathrm{PS}_{5-x} \mathrm{Br}_{1+x}$ calculated based on Equation 5 given in main text.

\begin{tabular}{cc}
\hline $\mathrm{x}$ & overall jump rate $\left(10^{9} \mathrm{~s}^{-1}\right)$ \\
\hline 0 & 24.5 \\
0.1 & 24.9 \\
0.2 & 25.4 \\
0.3 & 26.1 \\
0.5 & 32.6 \\
0.6 & 34.4 \\
0.7 & 35.8 \\
\hline
\end{tabular}

Reference:

(1) Sturniolo, S.; Green, T. F. G.; Hanson, R. M.; Zilka, M.; Refson, K.; Hodgkinson, P.; Brown, S. P.; Yates, J.

R. Visualization and Processing of Computed Solid-State NMR Parameters: MagresView and MagresPython. Solid State Nucl. Magn. Reson. 2016, 78, 64-70.

https://doi.org/10.1016/j.ssnmr.2016.05.004.

(2) de Klerk, N. J. J.; Rosłoń, I.; Wagemaker, M. Diffusion Mechanism of Li Argyrodite Solid Electrolytes for Li-Ion Batteries and Prediction of Optimized Halogen Doping: The Effect of Li Vacancies, Halogens, and Halogen Disorder. Chemistry of Materials 2016, 28 (21), 7955- 
7963. https://doi.org/10.1021/acs.chemmater.6b03630. 